\title{
THE GEOLOGICAL CONDITIONING OF HYDROCARBON EMISSIONS RESULTING FROM SOIL CONTAMINATION
}

\author{
Ewa J. Lipińska ${ }^{1}$ \\ 1 Subcarpathian Voivodeship Inspector for Environmental Protection Voivodeship Inspectorate for Environmen- \\ tal Protection in Rzeszów, Gen. M. Langiewicza 26 Str., 35-101 Rzeszów, Poland, e-mail:wios@wios.rzeszow.pl
}

Received: 2014.09 .12

Accepted: 2014.10 .27

Published: 2015.01.02

\begin{abstract}
Synchronization economy of oil mining and mineral waters is associated with planning the functions of spa treatment. Environmental protection of the spa areas also applies to preserve their technical and cultural heritage. This article attempts to determine the places of natural and anthropogenic hydrocarbon pollution substances. Their presence in the soil affects the quality of the environment. As a result, maps are produced showing directions of research: (1) the natural background of biodiversity, and (2) potential anthropogenic pollution. They are assessed in the context of the health and human life, protection of the environment and the possibility of damage to the environment. Research is conducted in communes of the status of the spa - for special protection.
\end{abstract}

Keywords: geology, hydrocarbon substances, mineral water, pollution, soil, environment.

\section{INTRODUCTION}

Substance is any chemical element and its compounds, except for radioactive substances, modified micro-organisms and genetically modified organisms. The substances are released, subjected to various forms of emissions and gradual partial inclusion in the geochemical cycle. These processes are varied and complex. They also have various forms: physical, chemical and biological (or hydrous, atmospheric or colloidal).

In the administrative practice, it is difficult to explain what level of substances in the environment is considered as natural - initial - normal. It is difficult to determine the natural range of their occurrences. The reason is different concentrations of their geochemical background in time and space.

Emission is the direct or indirect release of substances to the ground from individual or diffuse sources [Directive 2010]. Natural processes in the environment usually lead to a degradation or assimilation of these substances. Their volume, speed, emissions, short- and long-term toxicity must be taken into account when being entered into the environment. A self-cleaning of the environment is following and the restoration of its natural value but its usefulness is diminished. There is no risk of damage to the environment.

When the processes of the self-cleaning of the environment are too weak to overcome the influence of the substance with the forces of nature, a damage to the environment appears.

Damage to the environment is a negative measurable change in the condition or function of natural elements, evaluated in relation to the initial state [the Act 2007].

Soil is the top layer of the earth's crust situated between the bedrock and the surface. It is composed of mineral particles, organic matter of water, air, and living organisms. Most of soil is anthropogenically changed, although to a differentiated degree. For this reason, the determination of the natural concentrations of substances in soils and the soil pollution is complex.

Pollution is a direct or indirect introduction - as a result of human activity - of a substance, which may be harmful to human health or the en- 
vironment, dangerous to property, or which impair the environment, or interfere with other legitimate uses of the environment.

Partial results of the investigation of natural and antropogenic emissions of hydrocarbon impact on the environment is presented in the paper. The research covered areas of the communes with the status of the spa, i.e. Horyniec-Zdrój, Iwonicz-Zdrój, Rymanów and Solina. The maps of these communes show biodiversity and anthropogenic changes. The maps are made for the purpose of spatial planning.

\section{METHODOLOGY}

The object of research is the geological environment of communes of the status of the spa. Special rules of protection [e.g. the Act 2005 and 2007].

The aim of the study is to identify the geological conditions in areas of the communes of the status of spas, their soil and preparation of maps indicating the biodiversity, infrastructure and mining of mineral hydrocarbon materials.

The utilitarian aim is to identify the direct (potential, natural) and specific (anthropogenic) pollution in the areas of communes with the status of spa. The evaluation of the geological environment is made by analyzing data from state environmental monitoring. The object of study is a continuation and extension of the issues described in [Lipińska 2013].

\section{THE BEHAVIOUR OF LIQUID MINERAL DEPOSITS OF POLISH CARPATHIANS}

In Poland, Carpathians cover an area of ca $19,600 \mathrm{~km}^{2}$, i.e. $6 \%$ of the total area of the country. They are subjected to various forms of conservation. Protection of Natura 2000 in Polish Carpathians includes the Alpine biogeographical region, which covers an area of ca $10,050 \mathrm{~km}^{2}$.

Carpathians are composed of tracks flysch. A large variation of sediment thickness and intense tectonic disturbances is characteristic of this area. The occurrence of mineral resources is directly related with the respective geological structure.

In the central and eastern part of Carpathians deposits of mineral water and hydrocarbon substances can be found (Figure 1). Carpathian oil reserves are estimated at ca $27 \mathrm{~km}^{2}$ and natural gas at $16.5 \mathrm{~km}^{2}$.
Oil, natural gas and water are liquid natural resources. When these fluids surface or are exploited, their place is filled with the expanding substances. These are substances that remain in the fluid, including rock, or substances that flow into the bed of the external areas. The nature of inflowing material determines the basic energy system deposits. It determines the behaviour of the reservoir and its size.

Five systems of energy deposits of hydrocarbon substances was established. The actual active deposits is more than one power system (which is a mixed energy system).

The energy system of the deposit is determined on the basis of: (1) geological information, (2) the behaviour of the respective bores in the operating conditions, (3) the overall behaviour of the reservoir.

In Figure 2 examples of natural emissions of hydrocarbon were presented.

\section{THE RESEARCH PROBLEM - GEOLOGY, SOILS, BIODIVERSITY IN COMMUNES OF WITH THE STATUS OF THE SPA}

\section{The commune of Horyniec-Zdrój}

The commune of Horyniec-Zdrój lies within two geological units. The area is composed of Miocene deposits. These are mostly clay, covered by arrears clay, glacial sands and silty sands. Subsequently, sedimentary rocks of Cretaceous, as well as Tertiary sandstones and limestone are to be found. Single boulders, which are reminiscent of post-glacial are also found.

Mineral deposits are mainly represented by peat deposits, mineral deposits, deposits of marl, sand, sandstone and limestone. Peat mining area has an area of ca 550 ha and resources of about $380,000 \mathrm{~m}^{3}$. The mining area of mineral deposits is ca 180 ha. No deposits of hydrocarbon materials are reported.

The variability of soil and soil quality is a product of geological diversity of the commune of Horyniec-Zdrój. In this area podsoils, alluvial soil and brown soil evolved. In some places there are humus and peat.

In Figure 3, the biodiversity of the area of the commune of Horyniec-Zdrój is shown, as well as the distribution of mineral water wells and the limits of mining areas, against the backdrop of protected areas. 


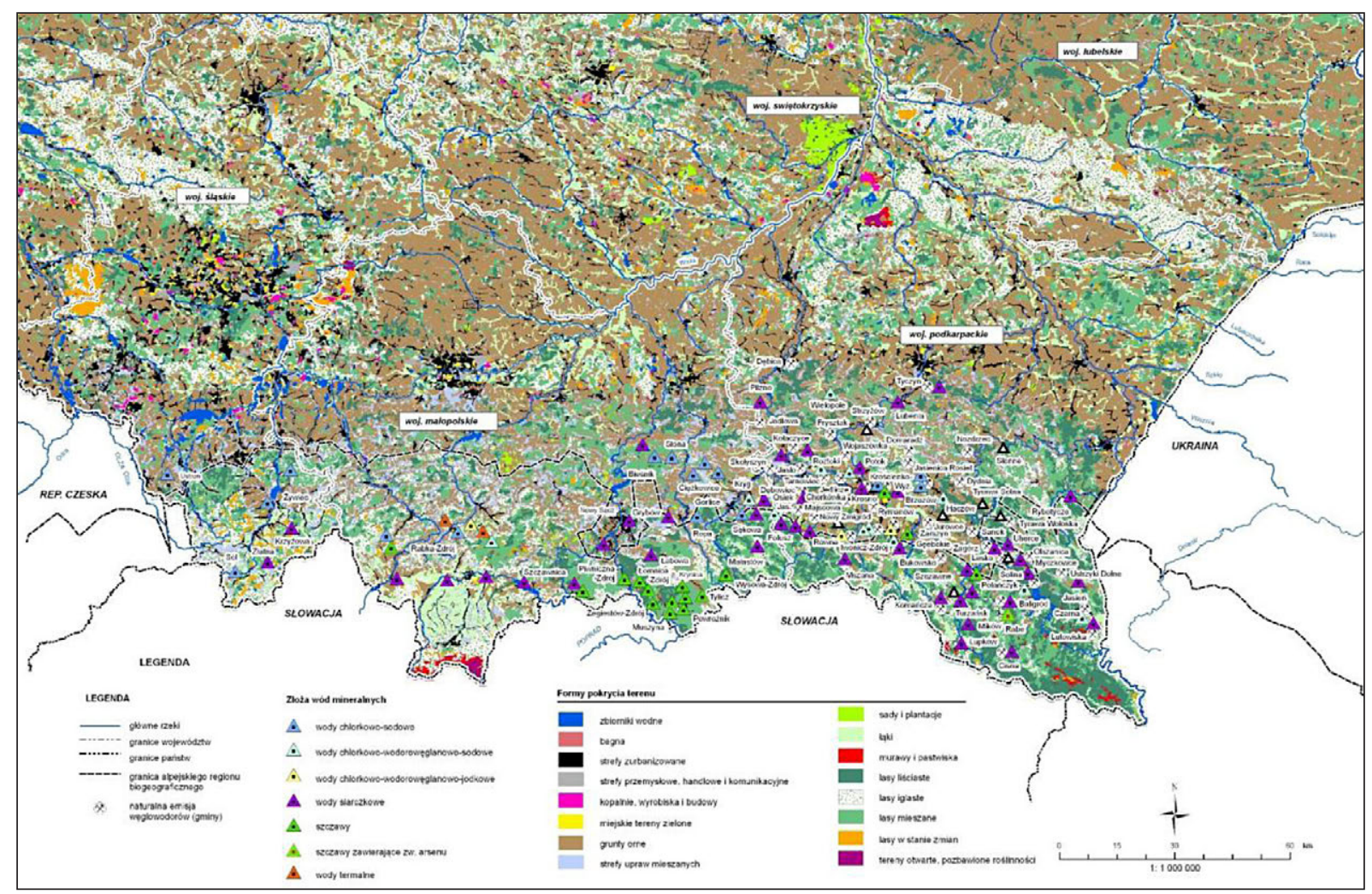

Figure 1. Polish Carpathians - forms of biodiversity in the area of the Alpine biogeographical region and location of deposits of mineral

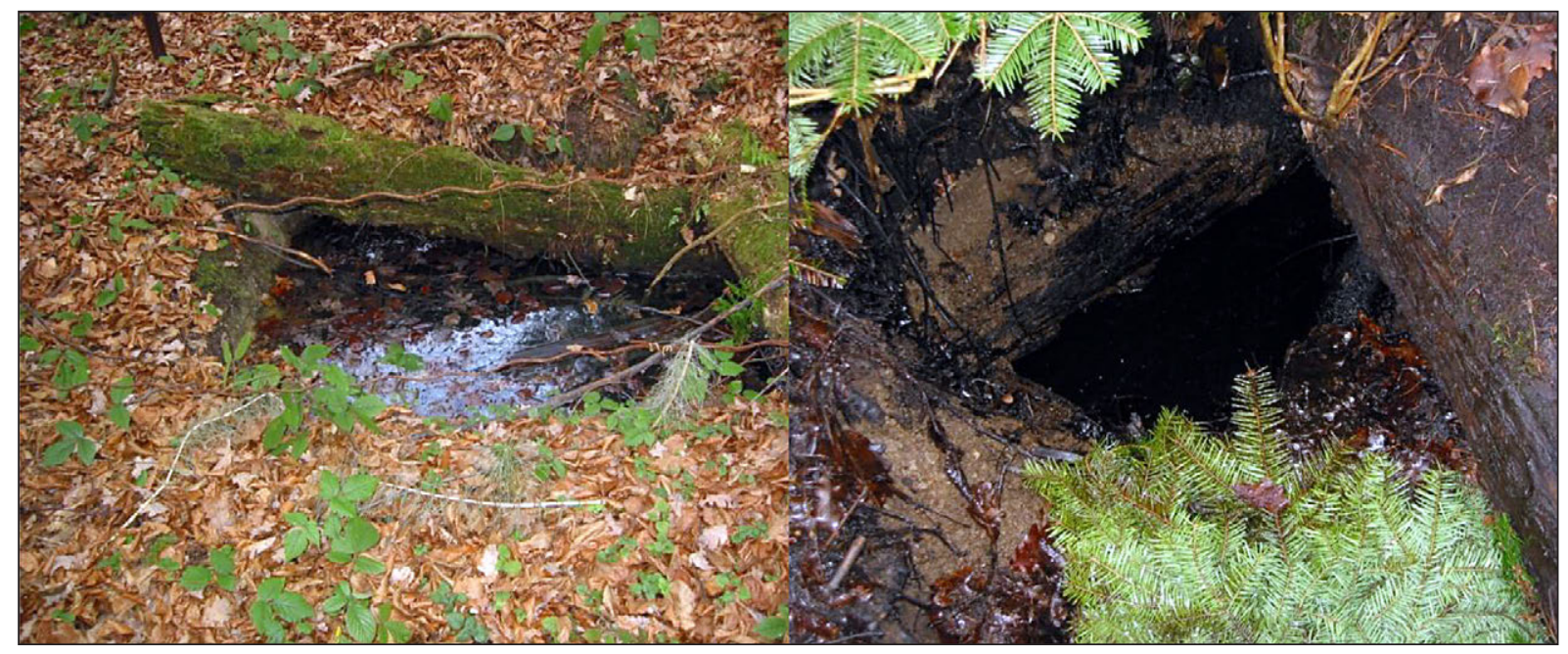

Figure 2. Well known kopanka with wooden housing; area of the village Turze Pole, the commune of Brzozów, Brzozów county, Subcarpathian voivodeship

\section{The commune of Iwonicz-Zdrój}

The commune of Iwonicz-Zdrój lies in the eastern part of Polish Carpathians. This mountain range, extending for ca $40 \mathrm{~km}$ long and 5 $\mathrm{km}$ wide, are built of works of Paleogene flysch and Cretaceous. Hard and resistant to weathering sandstones dominate there.
Figure 3. Kopanka; substitute area, the commune of Brzozów, Brzozów county, Subcarpathian voivodeship

The occurrence of mineral resources results from the geological structure. These are deposits of mineral water, oil and natural gas. Mineral waters are mined from two deposits. Two deposits of oil and natural gas are documented and expoited.

The beds of oil and gas are in sandstones. The variability of soil in this area is the result of its diversified relief. Soil weathering are character- 


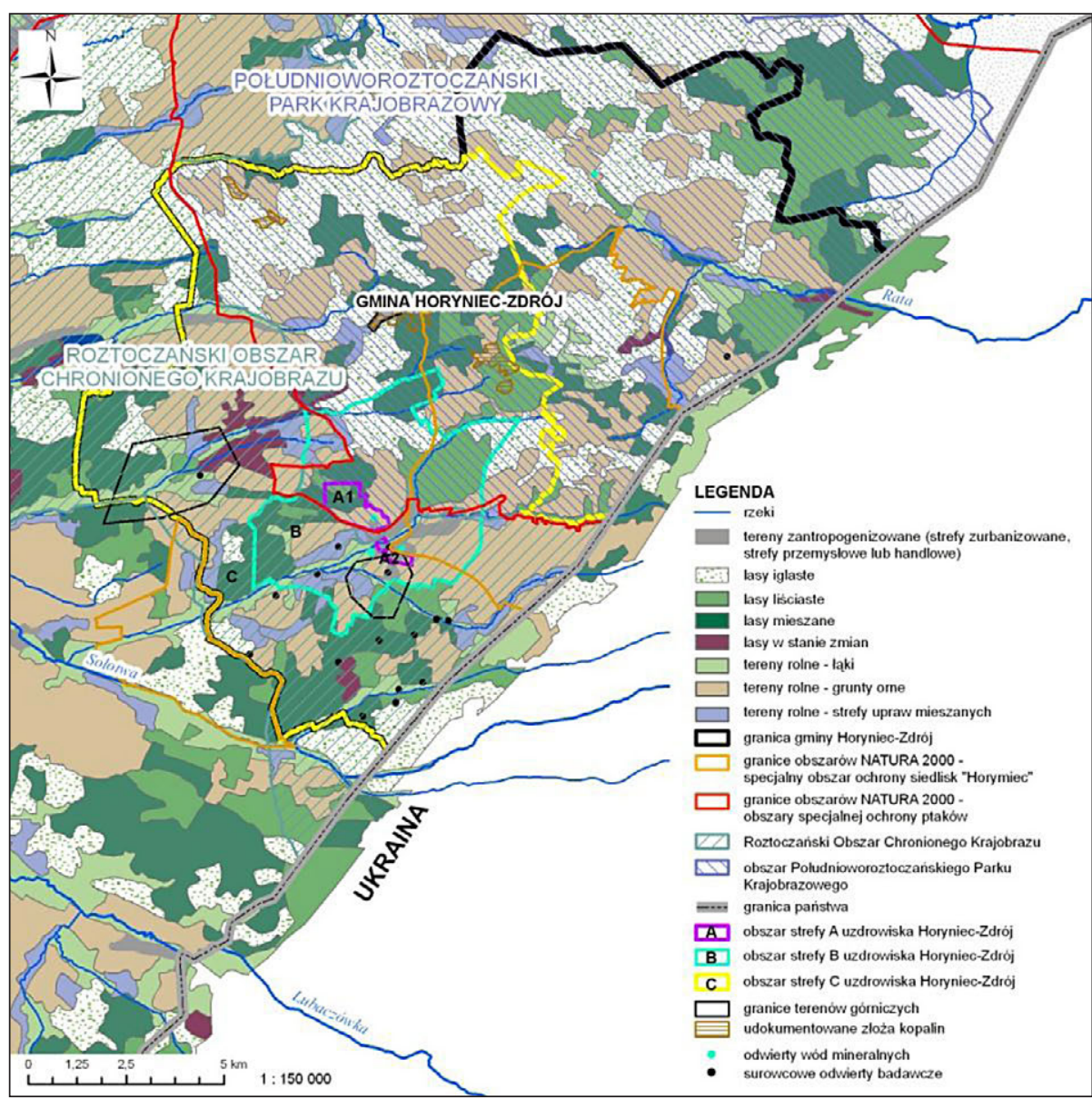

Figure 4. The commune of Horyniec-Zdrój - the distribution of biodiversity, mineral deposits, drilling research documented mineral deposits, the boundaries of mining; the Subcarpathian voivodeship

ized by granulometric composition aluminum, dust and silt. Brown soils dominate while alluvial soils occur locally.

The biodiversity of the area of the commune of Iwonicz-Zdrój is shown in Figure 4, location of mineral water intakes in relation to the areas of the occurrence of mineral deposits, active and liquidated drilling of oil and natural gas on the background of protected areas.

\section{The commune of Rymanów}

The commune of Rymanów lies in the eastern part of Polish Carpathians. The mountain range extends for ca $40 \mathrm{~km}$ long and $5 \mathrm{~km}$ wide. It is built of songs Paleogene flysch and Cretaceous. Upper Cretaceous sandstones are represented by layered slate. Tracks flysch sediments are covered by Quaternary sediments.

Natural resources are the raw materials of rock, mineral deposits, oil and natural gas. Soil variability is the result of diverse geological relief. Soil with a particle size of aluminum, dust and silt dominate. Brown and alluvial soils were produced.
In Figure 5 the biodiversity of the area of the commune of Rymanów is shown, as well as the location of sources and mineral drilling, oil drilling, natural resource exploration wells, the limits of the mining areas on the background of protected areas.

\section{The commune of Solina}

The commune of Solina lies within Eastern Carpathians. Sandstone layers with variable thickness of sediments dominate. Tracks flysch sediments are covered with quaternary deposits. The occurrence of mineral resources results from the geological structure. There are documented deposits of oil. Currently, wells are dismantled and the area is being reclaimed.

Exploitation of standstone was completed in 1991. Mineral waters are found in three horizons aquifers. This area is characterized by variability of soil due to the diversity of its relief. There exist soil particle size of aluminum, dust and silt. Brown soils and alluvial soils dominate. In Figure 6 the biodiversity of the commune of So- 


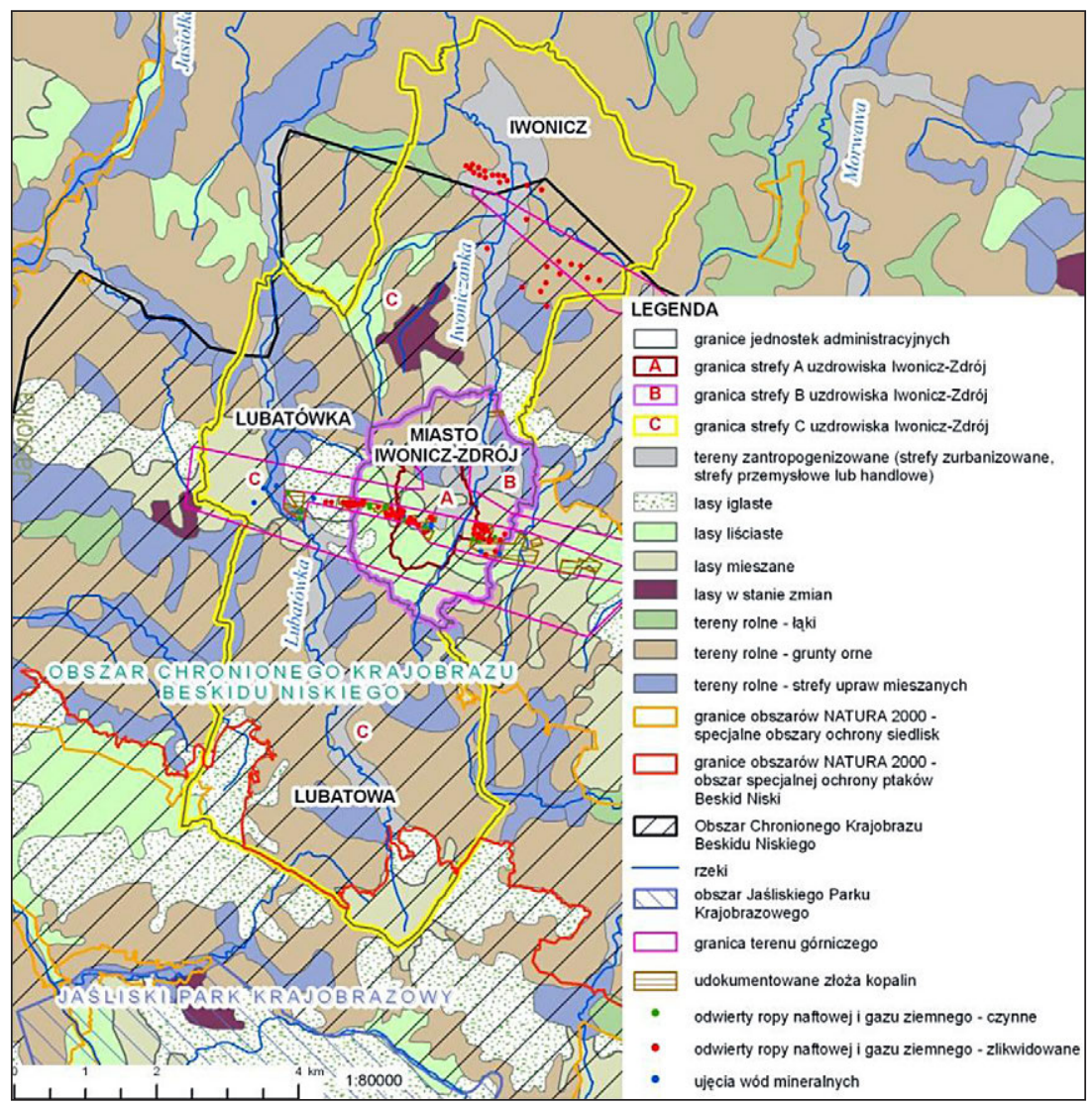

Figure 4. The commune of Iwonicz-Zdrój - the biodiversity, mineral deposits and hydrocarbon materials, liquidated and non-liquidated wells, the limits of the mining area; the Krosno county, Subcarpathian Voivodeship

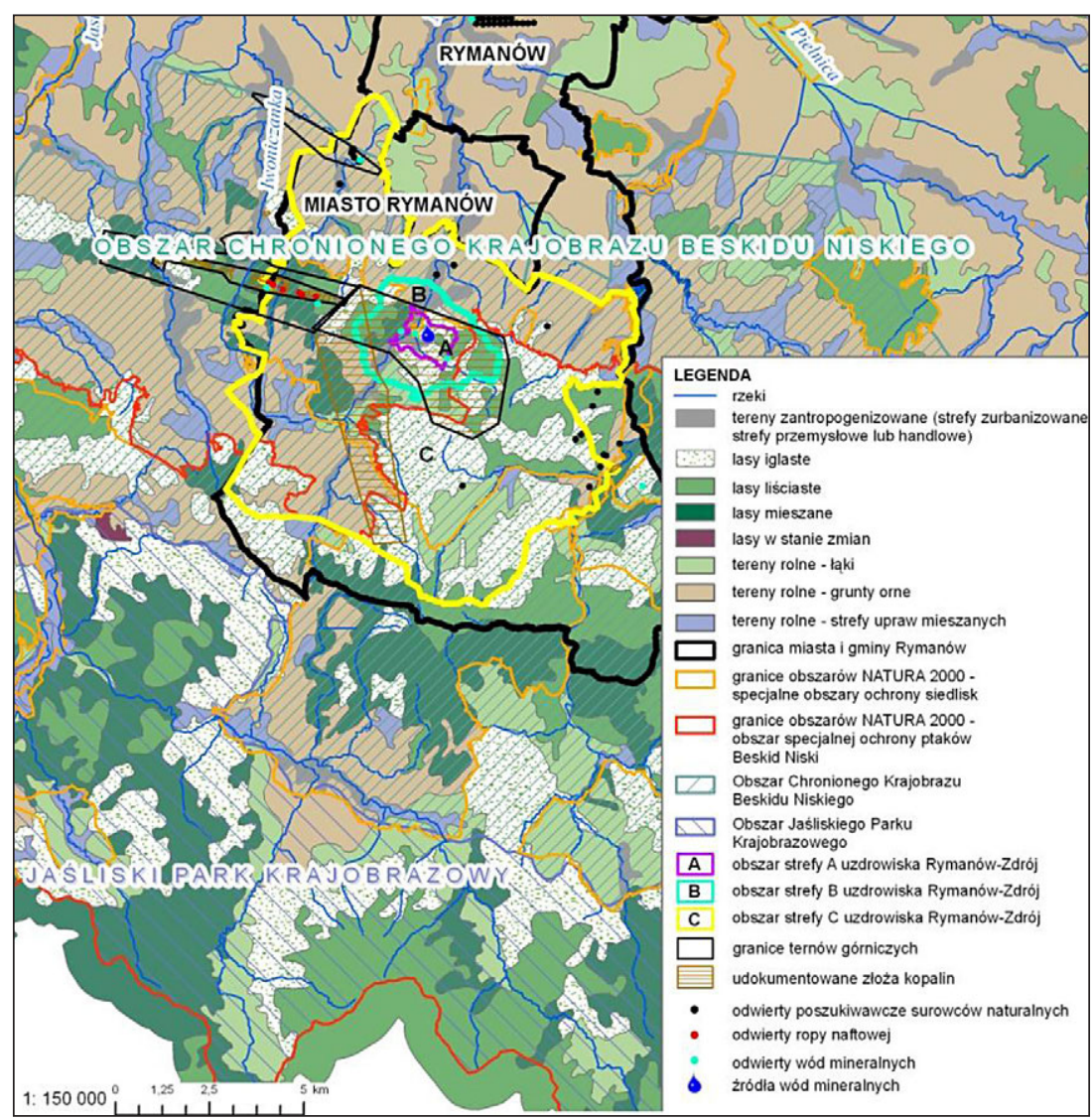

Figure 5. The commune of Rymanów - the distribution of biodiversity, mineral deposits and hydrocarbon materials, liquidated and non-liquidated wells, the limits of mining areas; the Krosno county, Subcarpathian Voivodeship 


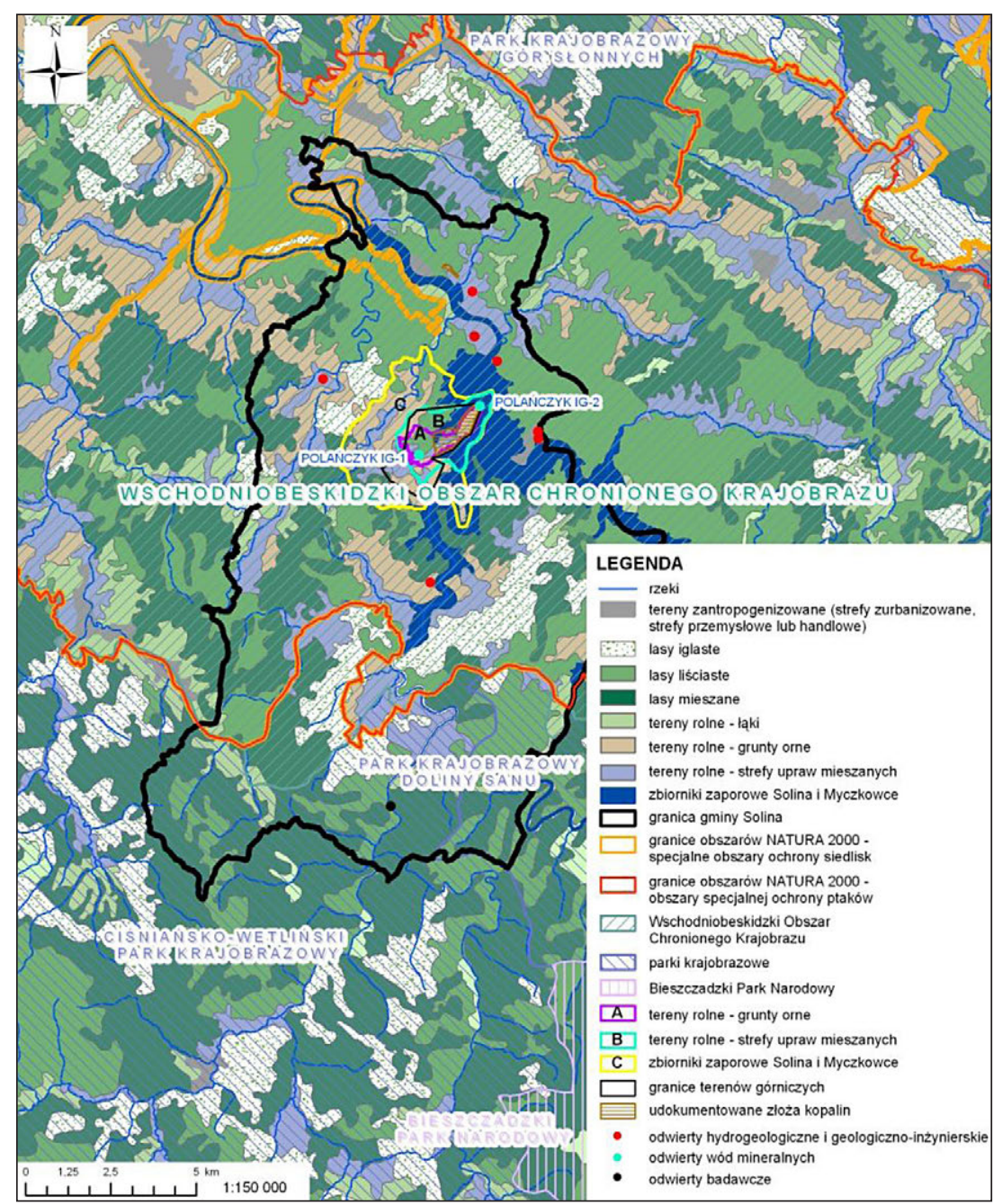

Figure 6. The commune of Solina - the biodiversity, mineral deposits, hydrogeological drilling, the limits of the mining area; the Lesko County, Subcarpathian Voivodeship

lina is shown, as well as the distribution of mineral water wells, the limits of the mining area, including the limits of the documented mineral deposits, against the background of the protected areas.

\section{CONCLUSIONS}

The proposed concept of studies seems satisfactory. The research goals specified in the Methodology section were reached. Postulates and conclusions are as follows.

1. The study is partial, reduced to the observation of only a certain part of the analysed statistical collectivity, geological environment of the health resorts. This requires a careful technical and organizational preparation of study.

2. Mineral resources whose extraction can contaminate soil were identified.
3. The studies expose information about warning, the indication of places, where natural and anthropogenic pollution currently exist and may occur in the future on the maps.

4. Maps have been elaborated, in which the area can be considered bi-directionally: (1) as a natural geochemical background, (2) as a possible anthropogenic pollution.

5. The research is addressed to the administration of communities with spa. The maps provide the original material for the development of the study of conditions and directions of the spatial development of the communes and the environment.

6. The owners of the technical infrastructure should find indicators on what work should be done to eliminate the direct and potential risks, eliminate their sources and reclaim the contaminated area to acquire hydrocarbon materials. 
7. The result of the co-occurrence of mineral deposits and those of hydrocarbon materials is the landscape and nature of spontaneous flora species richness, the composition of which often finds the occurrence of rare and vulnerable to extinction in the neighbouring areas. This wealth affects the behaviour and enrichment of the local biodiversity.

8. An important scientific contribution to the research is an interdisciplinary range of issues raised, concerning, inter alia, environmental engineering, environmental protection, geology and drilling.

9. A discussion of the impact of impurities remains, due to the size limitation of this paper within the scope of subsequent analyses.

\section{REFERENCES}

1. Directive 2010/75/EU of the European Parliament and of the Council of 24 Nov. 2010 on industrial emission (integrated pollution prevention and control) (Recast) (Text with EEA relevance) L 334/17.

2. Lipińska E.J. 2013. Distribution and environmental impact of emissions from co-occurring deposits of hydrocarbon materials from mineral deposits in the municipality of Iwonicz-Zdrój. Scientific Association of Social Space and Environment. Rzeszów.

3. The Act of 13 April 2007 on the prevention of environment damage and its repair (Journal of Laws No. 75 , item. 493).

4. The Act of 28 July 2005 on health resorts, spas and spa conservation areas and the municipalities spa (developed on the basis of Acts of 2012, pos. 651, 742). 